\section{TAMING A COTTONTAIL}

by Agnes Dobryoden, age 15, nford, Manitoba-Prize Winner

Tote: We have combined two letwhich Agnes wrote regarding tame Cottontail Rabbit. Her first er suggested that she had made he interesting observations so we ed her for further details. Agnes s us that they have seen CottonRabbits only recently in the Sand district. This and similar rets indicate that this animal is befound in new locations every $r$ and is apparently moving northrd. We will be interested in hearif any of you have seen this rabin your locality especially if it s first seen there only recently. $u$ will notice by the photo that it comparatively short ears and is bwn all the year. These are two tinguishing features which should ke it easy to recognize. The Cottail Rabbit, is, as a rule, a difult animal to tame but Agnes ems to have been quite successful doing so. Agnes' letter is as llows:

"With this letter I am enclosing photo of "Peter" the rabbit, eating carrot out of the hand. Carrots ere not his only food. He also enyed eating bread and toast. $\mathrm{He}$ ould eat anything remaining in the g's pan which would vary from rridge to soup. Some mornings we ould be delayed with his treats, id soon would see Peter peeking rough the window to see what was eeping us. That would be in win$r$ when the snow would reach the 1ls. When we would go out and ll Peter, he would come, no mat$r$ where or how far away he might ave been. Strangely enough, our $\mathrm{gg}$ would go chasing jack rabbits ver the fields all day, but would ever touch Peter. Often one would e the two together. When Peter ould be eating out of the dog's late, the dog would wait until eter had had his fill.
"We have noticed Cottontail Rabbits in our district only recently, perhaps in the last three years. These rabbits became fairly common and usually stay near farm buildings. In our yard we saw one adult and six or seven younger ones. Peter was easy to identify when he would come to us because he had a notch in one ear. There were about four other rabbits who would come up to eat after they would see Peter the rabbit come.

"This is how we tamed Peter. As a young rabbit we used to see him now and then about the farm buildings. Whenever we saw him, we would put out some small treatsfor example, wheat, meanwhile speaking softly to him and then quietly we would retreat. When we would be off a considerable distance we noticed Peter would aproach the grain and eat. Gradually he became accustomed to our presence and became tamer. Soon we were noticing him near the house. We continued offering him treats and always would always speak softly to him. Soon he became so familiar to us that he would come running to us. Then we tried offering treats from our hand. In a short time he was eating from the hand. One thing we noticed was the fact that once Peter was tamed, the other rabbits seemed to notice no harm was meant and tamed easily. We never picked the rabbits up but when we were feeding them we would pet their fur which was unbelievably soft. Even though the rabbits would eat the odd carrot greens, lettuce, dill, celery, peas and weeds, they didn't do any noticeable damage to the garden."

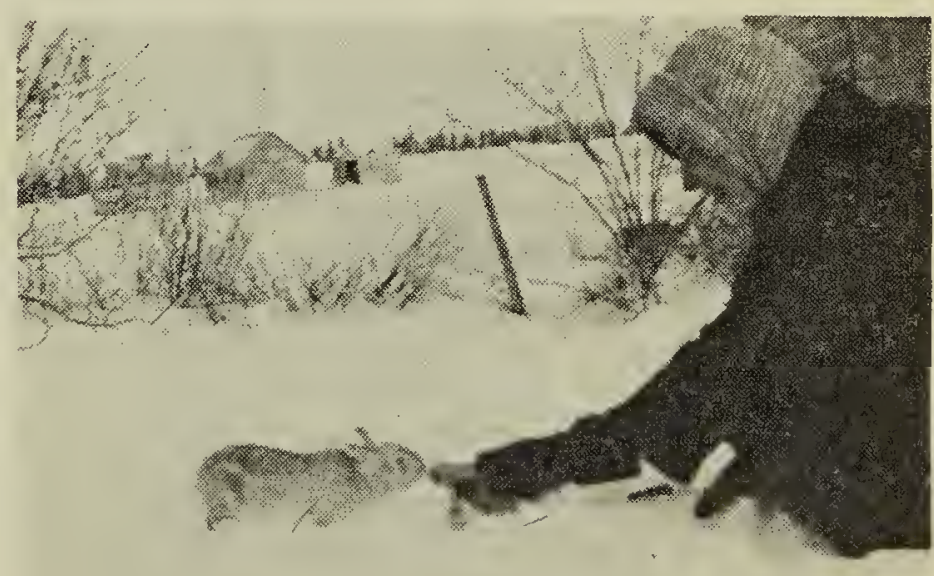

